\title{
A Study on the Applied Translation Talents' Training Mode Based on School-Enterprise Cooperation
}

\author{
Ying Shi \\ School of Foreign Studies, Xi'an University, Xi'an, China \\ 395475480@qq.com
}

Keywords: School-enterprise cooperation; Talent training mode; Translation talents

\begin{abstract}
With the rise of application-oriented undergraduate teaching, the construction of the talent training mode plays a crucial role in ensuring the quality of talents training. This paper finds problems in the training mode of school-enterprise cooperation by investigating undergraduates studying in translation majors/direction of School of Foreign Studies, Xi'an University, and tries to explore the mode of cultivating the translation talents based on school-enterprise cooperation.
\end{abstract}

\section{Introduction}

It is a win-win model for language service enterprises, universities, students and society, which also means new opportunities. It is a typical needs-oriented education mode that schools participate in the process of talent cultivation. In the cooperation, schools and enterprises have different roles. The current cooperation mechanism is not yet fully developed, and it's not really a win-win, and there's still a lot of problems in collaborative teaching. It is still worth deeply considering and exploring how to combine "learn" and "operation" of universities through cooperative teaching and students practice organically, and implement them in a long-term, stable, healthy, effective and deep scale, so as to develop special language service talents that meet the demand of economic and social development.

\section{Current Investigation and Analysis}

Purpose. This paper tries to analyze data through questionnaires, and find main problems exist in the training mode of school-enterprise cooperation, and then to explore applied translation talents Training Model.

Subjects. The subjects of this study were from the translation direction/major undergraduates of $\mathrm{Xi}$ 'an university, with a total of 70 questionnaires and 66 valid questionnaires, with an effective rate of $94.29 \%$. There are 25 students in the first year, 18 in the second grade, 16 in the third grade, seven in fourth grade. Although the subjects in this study were significantly different in age, gender and time of starting learning translation, they could comprehensively reflect the students' views on the needs of different stages of translation. It turns out that, whether they are freshmen or senior graduate students, there's no significant difference in the answer to the same five questions: most of the people think that they have a limited translation experience, and school-enterprise cooperation is important, which can lead to translation market directly, and they give high expectations. At the same time, from the survey, the researcher also find that there are some problems in the training mode of school-enterprise cooperation.

Data Analysis. In order to investigate the students' willingness and expectation to cooperate with the school-enterprise, the author designed a questionnaire to survey the students' needs in the school, among which the independent variables were in the grade, and the five questions were:

Q1. Whether students attend part-time translation.

Q2. Translation materials used in school teaching are consistent with translation market requirements. 
Q3. Adequate planning for his/her career development.

Q4. College internship opportunities for students to provide translation? The full score is 5 points. Please mark according to actual situation.

Q5. The college invites the relevant people in the field of translation to share their experience in the workplace, with a full score of five, and please rate it according to the actual situation.

This questionnaire is distributed to the students of translation majors/direction in Xi'an University, and the questionnaire survey is conducted from low to high points of the five-point scale from the first grade to the fourth grade in the university. As can be seen from the statistics, the results show that there is no significant difference in answering the same five questions, and that most of the respondents believe that their translation experience is deficient, and that it is very important to cooperate with the university-enterprise cooperation which is directly connected with the translation market, and that students have high expectation to achieve practical experience.

\section{Main Problems Exist in the Training Mode of School-enterprise Cooperation}

For students in the direction of translation, it is necessary to continue to be engaged in the practice, and effective mating between the translation direction and the enterprise requirement needs to be used as an important bond. After the formation of the school-enterprise cooperation model and the application in the practical process, it provides a platform for the students' practical learning. However, due to the lack of experience, the implementation effect of school-enterprise cooperation model is not satisfactory.

Obvious Formalization. In the translation direction of colleges and universities, the position of practice and theory is the same, which can realize the improvement of professional comprehensive quality level. At the present stage, the school-enterprise cooperation model has achieved the ideal development result, but still has obvious formalization. Among them, the fund support does not reach the designated position, and the direction of translation practice laboratory construction is severely neglected, which make it difficult to improve the students' practical ability effectively. Besides, from the perspective of enterprises, the school-enterprise cooperation model usually focuses on short-term interests, so the cooperative dynamic support is absent.

Insufficient "Double Qualified" Teachers. According to the actual research results, it can be found that the majority of the teachers in the translation direction of colleges and universities are theoretical research, which is crucial to the translation teaching, but the role of practice cannot be ignored. Especially under the social background of the transformation and development of institutions, the implementation of school-enterprise cooperation model still needs "double qualified" teachers as the main force. Based on the effective combination of practice and theory of school-enterprise cooperation model, it lays a solid foundation for the improvement of students' practical ability. However, the construction of teaching staff in colleges and universities is not ideal at this stage, and the lack of qualified teachers is seriously restricting the improvement of the practical effect of school-enterprise cooperation model.

Serious disengagement of practice content and training objectives. Under the background of school-enterprise cooperation, colleges and universities can make up for the deficiency of their practical teaching ability, and for students in the direction of translation, it is necessary to fully enhance students' own practical ability and translation practice skills. However, the vast majority of local colleges and universities still have serious disengagement in their teaching content and training objectives. From the perspective of practical teaching in translation majors/direction, the contents of internal practical teaching in universities and colleges are relatively simple, and the forms are very simple. They do not have a sound practice normative system and a restraint system, so the effect of practice cannot be guaranteed. 


\section{To Explore Applied Translation Talents Training Model}

To Meet the Demands of Market and Adjust the Training Objectives. With the changes of the times, the cultivation of today's applied translator talents must adhere to market orientation. In other words, the innovation and development of applied translation talents should proceed from the market demands, grasp the pulse of the times, and put the foothold and the goal point on the training of socially-needed and practical talents, so as to promote the cultivation of applied translation talents. Try to keep up with the times. It is not difficult to imagine that the cultivation of applied translation talents will be out of touch with the market or lag behind the market, and the cultivated talents will not be able to meet demands of market and adapt to the development of the times. Market-oriented, in line with the trend to develop education, we can turn educational potential into productivity and promote educational development.

Translation talent training should meet the needs of social and economic development. Any kind of application-oriented training mode must be guided by social needs and highlight the characteristics of "application". Targeting training objectives in "high-level, applied, and professional translators and translators who are able to meet the needs of the country's economic, economic, and social development and meet the needs of the nation's economic, social, and social development". It is adhering to the "demand-oriented" concept, and it closely combines talent cultivation with social needs. Therefore, the cultivation of applied translators should be guided by market demand.

To Reform Teaching Mode and Adjust Course System. First of all, the application of translation courses should be centered on improving translation skills and courses should aim at improving translators' capabilities. Translator training must first focus on the study of translation theory. Mona Baker pointed out that theoretical learning does not necessarily ensure that everyone is successful. Its value lies in the fact that the risk can be reduced to the minimum, and subjective judgments can be reduced. Self-confidence can lay a good foundation for further development in the field of translation. Only by improving the theory can we improve the ability and proficiency of translation. At the same time, translation practice should be carried out under the guidance of theories. The large number of translators and educators in universities should strive to create conditions for the cultivation of applied translators and actively establish on-campus and off-campus practice training bases.

Secondly, the special skills requirements for the translation profession cannot be completed by the general foreign language training model. It is necessary to introduce the particular training mode of translation. In foreign countries, many countries have achieved great success in cultivating translators. Foreign colleges and universities adhere to the market demand as the guide for the training of translation talents. Focus on cultivating translation practical ability in terms of training objectives, curriculum system, faculty, evaluation criteria, etc. About 270 universities and colleges in the world have translation teaching and research projects. Since the 1970s, they have trained specialized interpreters and translators.

To Build a "School-enterprise Cooperation" Mode. Translation as a profession, whether part-time or full-time, has a high degree of specialization, and is highly applicable and operational. Therefore, the training of applied translators should be based on the talents training model of "school-enterprise cooperation" in vocational and technical education, making full use of the two different education environments --- educational resources and enterprises, and realizing the organic integration of classroom teaching and corporate reality. Jiang Yonggang, deputy secretary general of the China Translation Association, also believes that "a high level of translation requires two stages--- school education and vocational training. Translation involves all aspects of knowledge. The professionalization of translators depends more on his work. The ambitions and the actual experience accumulated in the process of "professionalization." The training of translators should reflect local and applied characteristics. According to the needs of the translation industry in the region, the translation course itself is very practical. For this reason, universities and colleges establish cooperation mechanisms with various types of foreign capital, joint ventures, foreign 
companies, tourism companies, foreign-related institutions or professional translation companies and industries, as well as industry-university-research institutes, and try to build an internship platform for students to provide various practical opportunities. Students can effectively apply the theoretical knowledge and practical skills of their studies to use. This is of great significance for training applied translators.

To Build Translation Workshop. The Translation Workshop is similar to a commercial translation center with two or more translators working together to participate translation activities. Applying the "translating workshop" practice model to translation teaching can not only enable students to understand the skills needed for real translation work, but also can train students' translation skills and cultivate students' teamwork spirit. The interest of students can be motivated which enables them to participate actively in more translation practices. Translation workshops are guided by translation projects. Students are the central subjects of translation practice activities. Teachers are organizers, coordinators, supervisors, and guides in the operation of translation workshops. At present, a translation workshop has been built in Xi'an University, equipped with computer-aided video translation software and hardware facilities. The instructors are trained by the Translator of the Transit Company. The translation tasks can be simulated projects or real projects. The students are free to form a number of translation teams. Each team member distributes their own role to complete the entire translation process, including contact with the customer - to undertake the project - the assignment of translators - translation - quality inspection - review typesetting - proofreading - delivery of translation - tracking customer opinion. After the translation task is completed, each team presents the team's translation results, summarizes them, and accepts questions and comments from other teams. The instructor finally analyzes, comments, and summarizes each team's translation completion status, and gives scores, which are included in the results of the process assessment. The translation work is managed according to the actual project management methods, and the students complete the tasks under the guidance of the teacher. Establishing a translation workshop can improve teachers' and students' translation practice abilities and enable students to familiarize themselves with translation software and hardware operations and translation business processes that are commonly used in the translation industry. Upon graduation, students can immediately take up posts and be qualified for translation work. The company provides paid translations for teachers and students. The translation workshop teaching method highlights the practice and application of the translation profession. Teachers also gain more practical experience in teaching.

To Strengthen the Construction of "Double Qualified " Teachers. The training of applied translators depends not only on the translation course system and teaching model, but also directly on the teachers. Strengthening the construction of "dual-qualified" teachers will not only improve the quality of translation teaching, but also form the characteristics of the training of applied translators. To strengthen the construction of "dual-qualified" teachers must look at the overall situation, broaden their horizons, grasp the key points, and advance with the times, and encourage teachers to participate in various social practices in various forms. The construction of a team of teachers engaged in application-oriented translation training should comprehensively improve teachers' overall quality and social practice ability.

\section{Conclusions}

With the rise of application-oriented undergraduate teaching, the construction of the talent training mode plays a crucial role in ensuring the quality of talents training. This paper finds problems in the training mode of school-enterprise cooperation by investigating undergraduates studying in translation majors/direction of School of Foreign Studies, Xi'an University. Colleges and universities should identify market entry points combining the national economy, regional economy and local economy and cultivate applied translation talents. Efforts are made to innovate the application-oriented training model of translation talents, to build application-based translation 
talents, to develop online education platforms, to build translation talent pools with application-based translation talents, and realize integration of production and study among governments, enterprises and schools on the basis of talent exchange and language services.

\section{Acknowledgements}

This research is sponsored by Xi'an University Fund Project for curriculum reform (JG2017002), and by the Shaanxi Province Education Science 13th Five Year Plan (SGH17H231).

\section{References}

[1] Shen Lijun. Deep University-enterprise Collaboration in Cultivating BTI Talents_-Taking the Example of Fuzhou University of International Study and Trade. Journal of Jilin Agricultural Science and Technology University. (2016) (In Chinese)

[2] Zhang Mingfang, Guan Bo, Yan Yalin,Chen Yuxi.Constructing Competence-oriented BIT Course Modules_—_Based on Students'Needs Analysis.Journal of Hebei University of Science and Technology. (2017) (In Chinese)

[3] Jia Liping. A Study on the Training Mode of School-Enterprise Cooperation Based on the Cooperation between Translation Majors and Translation Company. Journal of Higher Education. (2015) (In Chinese)

[4] Gentzler, Edwin. Contemporary Translation Theories. London: Routledge, (1993)

[5] Xu Han. A New Training Model for Practical Personnel in the Program of MTI. Journal of Nanchang Hangkong University.(2017) (In Chinese)

[6] Yang Qiong. Problems and countermeasures in the cultivation of English translation talents. Journal of Hunan University of Science and Engineering.(2016) (In Chinese)

[7] Feng Xiaolei. The Training of Translation Talents under the Cooperation of School-Enterprise. Theoretic Observation.(2016) (In Chinese) 